\title{
Strategic Directions for the Water Resources Division, 1998-2008
}

U.S. Geological Survey Open-File Report 99-249 



\title{
Strategic Directions for the Water Resources Division, 1998-2008
}

\author{
By U.S. Geological Survey
}

U.S. Geological Survey Open-File Report 99-249 


\title{
U.S. DEPARTMENT OF THE INTERIOR BRUCE BABBITT, Secretary
}

\author{
U.S. GEOLOGICAL SURVEY
}

Charles G. Groat, Director

For additional information write to:

Acting Assistant Chief Hydrologist for Office of Information U.S. Geological Survey National Center 12201 Sunrise Valley Drive

Reston, Virginia 20192
Copies of this report can be purchased from:

U.S. Geological Survey

Information Services

Box 25286

Federal Center

Denver, CO 80225 


\section{CONTENTS}

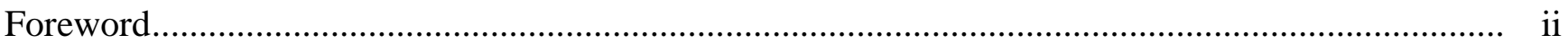

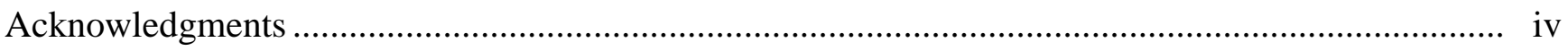

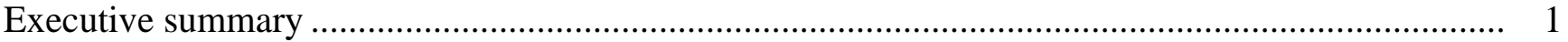

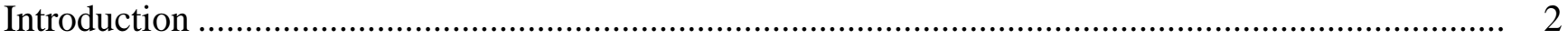





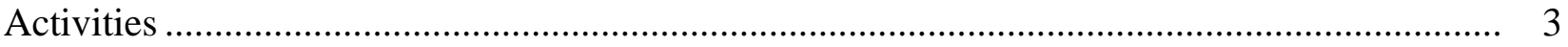

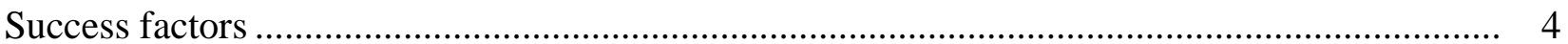

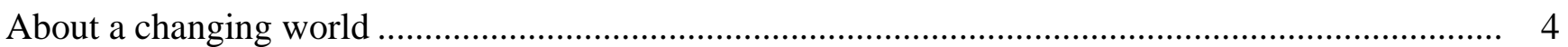

Strategic directions in Water Resources Division scientific activities .............................................. 6

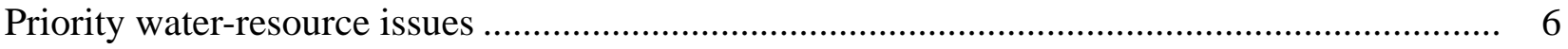



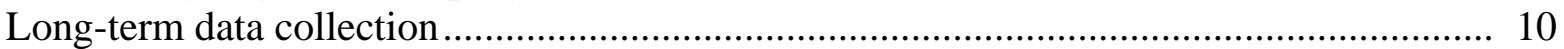

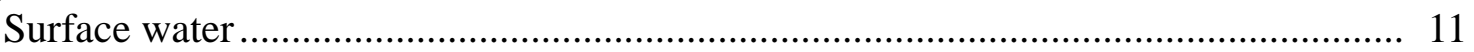

Ground water ......................................................................................... 11

Water quality ........................................................................................... 12

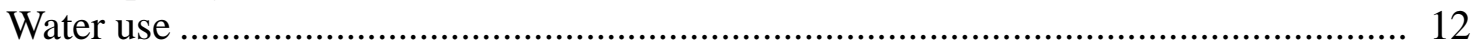

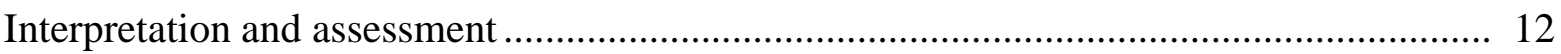

Research and development ..................................................................................... 13

Balance among major program components …………………..................................... 14

Balance among discipline areas ............................................................................. 14

Investments in new capabilities ....................................................................................... 15

Field and laboratory methods .................................................................................... 15

Instruments and technology ..................................................................................... 16



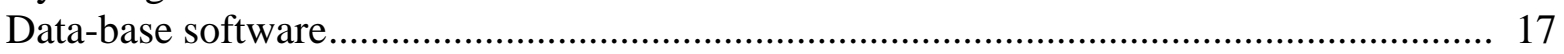

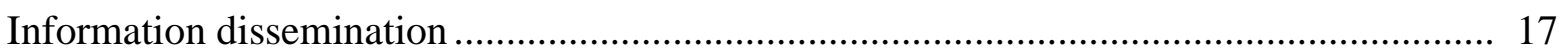

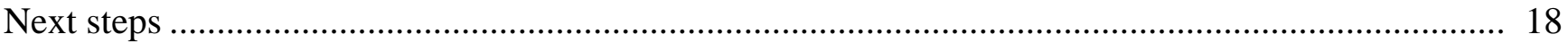




\section{FOREWORD}

This document articulates what the authors hope will become a shared vision of the future directions for the water-resources activities of the U.S. Geological Survey (USGS) for the years 1998-2008. The word "shared" is critical here for three reasons. First, the vision must be shared among the leadership and all employees of the Water Resources Division (WRD). WRD has a highly distributed workforce and a management structure that delegates major responsibility for program development and for scientific, fiscal, and workforce management to field-based units. If we are to move in new directions, headquarters leaders, fieldbased leaders, and the entire workforce must be involved in the process of setting the directions and must fully understand and support them.

Second, we want to make sure that the vision is shared across the whole of the USGS. We believe that the future success of the USGS in fulfilling its mission depends on drawing on the strengths of all divisions to fulfill the Nation's needs for information on issues of hazards, environment, and resources. Biologic, geologic, and mapping expertise must be brought to bear on water-resource issues, and conversely, we should bring our hydrologic expertise to bear on the mission needs of those programs.

Finally, our hope is to present a vision that can be shared by the wide range of our stakeholders - the potential and current customers, partners, and users of the water information we produce. Stakeholder views were represented in setting our strategic vision through participation of WRD managers who interact with these stakeholders on a regular basis. We got more direct input during the review process when this draft document was presented to a wide range of outside entities for review and comment. Through this process we got their reactions and heard their concerns and (or) agreement and made modifications to incorporate their views about the USGS and about the future. It is our hope that this document is as much their vision as it is ours.

What are some of the major thoughts that define our strategic directions?

We believe that WRD is a strong and healthy organization. We have a talented and motivated workforce that is able to address a wide range of important issues. Water is vital to the Nation; thus, there will continue to be significant demands for the kind of information we produce.

We have made major changes in what we do and how we do it in recent years. We will continue to make major changes in the years to come. Examples of recent innovations include-

- Delivery of real-time streamflow data.

- Research on bioremediation.

- Integration of geographic information system technology into virtually every study we do.

- Capability to sample and analyze for many chemicals at environmentally relevant concentrations.

- Ability to age-date young ground water to help predict the movement of contaminants and to quantify recharge.

- Incorporation of biology into many investigations.

- Use of the Internet to disseminate many of our products (real-time and historical data, models, and reports).

- Use of new acoustic methods for measuring streamflow and river-bed scour that allow us to provide data that were virtually impossible to collect in the past.

- Streamlining of many administrative and publication policies and procedures so that we do our work and deliver our products in a more timely manner.

We come to this process of charting our strategic direction with a view that we are a strong and resilient organization, doing highly relevant work. It is important, however, not to be complacent. The planning process was designed to get us to take stock, to look around at the world in which we operate today and the changes we might expect in the next few years. We see real challenges. The role of government at all levels is questioned by some, and funding has not matched inflation in recent years. As a result, we have had to reduce the level of our programs. We also need to clarify the role of WRD in a time when the private sector has greater skills in hydrology than ever before.

We believe we have strengths that will allow us to meet the challenges.

1. The first strength is our people with their motivation, skill, and the broad and deep scientific and technical knowledge that they embody from many years of experience and education. 
2. Our infrastructure of monitoring capabilities and instruments, data bases, models, standards, and special purpose facilities for chemical analysis and field instrumentation serves as a solid base for future work.

3. We are part of the USGS, a strong scientific organization with the capability to address a broad range of natural science issues that involve hazards, resources, and environment. Our ability to collaborate with our colleagues in the Geologic Division, the Biological Resources Division, and the National Mapping Division gives us strength through the breadth of capabilities present in the USGS.

4. We have strong and growing opportunities for collaboration with other Federal Agencies, most notably the U.S. Environmental Protection Agency, the National Weather Service, U.S. Army Corps of Engineers, and the Federal Emergency Management Agency; with the resourcemanagement agencies in the U.S. Department of the Interior; and with the academic community, especially through the Water Resources Research Institutes.

5. The many customers and partners-whose numbers and fiscal contributions to WRD continue to grow even during this time of general downsizing of government-are an important source of strength.
This strategic planning document sets forth where we want to be in 10 years. Our intent in preparing it was to make sure that we capitalize on our existing strengths to be even more successful 10 years from now than we are today. We believe that this document contains ambitious goals that will cause all of us to reach beyond and exceed our expectations. The document is not a detailed implementation plan. Attaining the goals set forward will come about through internal planning efforts, working with others to find resources to achieve some of the goals, and making the right choices about what new activities to begin when old activities end. Even before this document was completed the strategic planning process had many impacts on decisions that division leadership made regarding staffing issues, program priorities, and scientific and technological investments. For each of the directions and activities described here, we will continue to draw heavily on the good ideas of teams of our employees to help us prepare implementation plans that will describe the exact path to our future.

\section{Robert M. Hirsch (signed)}




\section{Acknowledgments}

Elizabeth Fellows, U.S. Environmental Protection Agency; Debra Knopman, Progressive Foundation; and Stephen Parker, National Research Council, helped the planning team to think about factors that could affect water resources in the United States and the world in the future. An early draft of the document was read and critiqued by WRD employees: Jeffrey Armbruster, Jerad Bales, Robert Boulger, Michael Dettinger, Warren Gebert, Dennis Lynch, Donna Myers, Donald Thorstenson, and Deborah Weldon. This team's thoughtful review resulted in modification of both content and style to make the messages of the document clearer to readers. Jo Ann Macy improved the clarity and readability of the document through careful editing.

During the review process, we received specific comments on the document from over 200 individuals from within the USGS and from external stakeholders. We thank each of them for taking the time to read the document and to share their perspectives. This final version of the document has been much improved by their thoughtful comments.
The WRD Strategic Directions Team included:

$\begin{array}{ll}\text { Robert M. Hirsch } & \text { David J. Lystrom } \\ \text { William M. Alley } & \text { Gail E. Mallard } \\ \text { Mary Jo Baedecker } & \text { Wanda C. Meeks } \\ \text { William J. Carswell, Jr. } & \text { Timothy L. Miller } \\ \text { T. John Conomos } & \text { Brian R. Mrazik } \\ \text { John E. Costa } & \text { James G. Peters } \\ \text { John N. Fischer } & \text { David A. Rickert } \\ \text { Timothy W. Hale } & \text { Verne R. Schneider } \\ \text { Catherine L. Hill } & \text { Lewis V. Wade } \\ \text { William F. Horak, Jr. } & \text { Janice R. Ward } \\ \text { Samuel N. Luoma } & \text { Thomas H. Yorke, Jr. }\end{array}$




\section{STRATEGIC DIRECTIONS FOR THE WATER RESOURCES DIVISION, 1998-2008}

\section{EXECUTIVE SUMMARY}

The Water Resources Division of the U.S. Geological Survey is a strong and healthy organization. We do important and highly relevant work and have many strengths that will help us to meet the challenges and take advantage of the opportunities before us. We are part of the U.S. Geological Survey, a national science organization with the ability to address the most complex scientific and technical issues facing the Nation. We have ongoing collaborations with the larger scientific community to address the most important problems in the science of hydrology. We have a strong base of cooperators, including Federal, State, and local agencies who help us address issues of mutual interest. Without the support of all of these partners, we could not achieve our mission.

This document presents three major premises that will guide the division over the next 10 years (1998-2008): (1) we will maintain and strengthen our scientific excellence and our partnerships; (2) we will make adjustments in skill mix, program emphasis, and approaches to staffing; and (3) we will maintain the flexibility to respond appropriately to unforeseen events.

As we look into the future, we believe that nine water-resource issues will receive increased attention from the hydrologic community and need increased emphasis from us-

- Effects of urbanization and suburbanization on water resources.

- Effects of land use and population increases on water resources in the coastal zone.
- Drinking water availability and quality.

- Suitability of aquatic habitat for biota.

- Waste isolation and remediation of contaminated environments.

- Hydrologic hazards.

- Effects of climate on water-resources management.

- Surface-water and ground-water interactions as related to water-resources management.

- Hydrologic system management, including optimization of ground-water and surfacewater use.

We will make changes in our existing major program components-long-term data collection, interpretation and assessment, and research and development - to make them more effective. We recognize the strength that comes from having these program components in the same organization and will take action to improve linkages among them. We will make important short-term investments in new tools and capabilities to improve our field and laboratory methods, instruments, hydrologic models, database software, and information dissemination. We will significantly improve transfer of technology to our operational program.

We also will take action to restore balance among programs and among discipline areas. During the last 15 years, there has been significant growth in the interpretation and assessment component of our program. This is a very important part of our work and should be a significant percentage of the overall program 
because the products of our interpretive studies are directly and immediately relevant to decisionmakers. Our program in long-term data collection, however, has decreased as a percentage of our work to the point where it is too small a part of our overall effort. Therefore, we will work with the U.S. Department of the Interior, the Office of Management and Budget, and the Congress to shift our program balance to increase the percentage of funds available for long-term data collection. Similarly, we will work to increase the percentage of our overall effort directed toward ground-water and surface-water quantity so that we can improve our ability to meet both current and future needs.

\section{INTRODUCTION}

This document identifies goals and outlines strategic directions; it is not a detailed implementation plan. Ideas in this document will be implemented over time with the insight and guidance of our employees, our colleagues, and our customers and partners.

This document describes the mission and the future directions of the Water Resources Division (WRD) of the U.S. Geological Survey (USGS). The initial draft of the document was prepared by a planning team that consisted of 22 senior managers and scientists from WRD. A large number of stakeholders improved the document through an extensive review process. We received comments from within WRD, and from other divisions of USGS, Department of the Interior (DOI) management and bureaus, other Federal agencies, State and local agencies, the academic community, and the private sector. The document was revised to respond to the concerns and support of these stakeholders. The primary audience for the document is internal, as it will help guide decisions at all levels of our organization. However, our stakeholders have indicated that they will find it helpful as they work with us to address issues of mutual concern.
"Strategic Directions for the Water Resources Division, 1998-2008" presents three major premises. First, we will maintain and strengthen those characteristics of scientific excellence, strong partnerships, and program balance that have been key to past successes and will be key to future success. Second, we will make adjustments in skill mix, program emphasis, and approaches to staffing that will improve our current and future position as a leader in hydrologic data collection, investigations, and research. Finally, we will maintain the flexibility that will allow us to anticipate and respond appropriately to unforeseen events. This document combined with other policy documents, is a compass that can be used by division decisionmakers to steer the organization in a positive direction.

This document complements and shares many of the attributes highlighted in the 1996 USGS Strategic Plan; however, the two documents differ in their scope. The USGS Strategic Plan gives general guidance for the bureau as a whole, whereas the WRD document provides detailed and specific directions applicable to the WRD.

The planning horizon for this document is 1998-2008. Within that timeframe, we identify some specific actions that will be accomplished in the near term. For example, we identify some high-priority activities that we will undertake within the next 5 years to improve our current capabilities. We anticipate that some changes and mid-course corrections may be necessary during the next several years as unforeseen events occur. Because most of the decisions that affect our stakeholders and human and financial resource allocations are made in WRD district offices, research branches, and other major field offices, it is important that all of these decisionmakers share a common understanding of who we are, what we stand for, and what our goals are for the future. Only then can WRD move in the directions outlined here and respond appropriately to signals in the external and internal environments that might require a shift in course. 
At several places in the document, we identify target percentages for various activities. These percentages were arrived at through a consensus process using the planning team's collective expertise and records of WRD's mix of activities during the last 15 years. The target percentages apply to WRD as a whole, not to individual organizational units. They are not rigid requirements that will drive all decisions. Instead, they are guidelines that will help us track our progress towards an improved and better-balanced future.

"Strategic Directions for the Water Resources Division, 1998-2008" begins with a statement of the mission, activities, and success factors of the WRD in 1998 and then proceeds to consider changes in the global environment and in water-resources management that are likely during the next decade. Given a changing world, the section "Strategic Directions in Scientific Activities" of this document outlines waterresource issues that need increased emphasis, planned evolution of ongoing programs, and some short-term investments that are necessary to enhance current capabilities.

One theme that runs throughout the document is the requirement for us to listen to the needs of our stakeholders, which include the technical community who manage the Nation's water resources and Federal, State, and local regulatory agencies and land managers. We must design and conduct the best and most relevant science to meet the needs of these stakeholders. We must make the results of our scientific efforts available to them in a timely manner and a form that is most useful to them.

\section{WATER RESOURCES DIVISION IN 1998}

WRD's mission and activities define the organization and distinguish it from other scientific or governmental organizations.

\section{Mission}

The mission of WRD is to provide reliable, impartial, timely information that is needed to understand the Nation's water resources. WRD actively promotes the use of this information by decisionmakers to-

- Minimize the loss of life and property as a result of water-related natural hazards, such as floods, droughts, and land movement.

- Effectively manage ground-water and surfacewater resources for domestic, agricultural, commercial, industrial, recreational, and ecological uses.

- Protect and enhance water resources for human health, aquatic health, and environmental quality.

- Contribute to wise physical and economic development of the Nation's resources for the benefit of present and future generations.

\section{Activities}

Consistent with the accomplishment of our mission, WRD provides impartial, credible, and excellent science that is applied to issues relevant to water-resources management, protection from hydrologic hazards, environmental protection, and other public policies. In a world with many competing demands on water resources and considerable public attention to water issues, it is important for WRD to identify its primary strengths, establish priorities, do the things necessary to best serve the Nation, and do them extremely well.

Primary WRD activities include-

- Collecting, quality assuring, storing, and disseminating basic hydrologic data on the quantity and quality of water.

- Conducting assessments of availability of water, quality of water, water use, and waterrelated hazards at scales that range from single data-collection sites to regional and national scale. 
- Conducting interpretive studies and developing predictive models that describe the potential consequences of water-related management actions.

- Providing knowledge and expertise to assist various levels of government (Federal, State, and local) in understanding and solving critical water-resources problems.

- Developing new methods for acquiring waterresources information, including methods of data collection, quality assurance, data management, laboratory analysis, data analysis, and simulation modeling.

- Producing new understanding that describes or explains processes important to water-related issues.

\section{Success Factors}

There are several success factors upon which WRD depends for current and future success.

- WRD does high-quality and cost-effective work. We produce products that are timely and useful to their intended audience.

- WRD is responsive and relevant to the information needs of its many partners and of the Nation. We anticipate important issues and develop knowledge of them in advance of public concern; this strategy allows rapid response when issues emerge.

- WRD has a workforce with both long-term stability and flexibility to address the Nation's water-resource issues. Careful hiring, availability of training, and a rewards system establishes a base of dedicated permanent employees whose skills are supplemented with those of a nonpermanent staff.

- WRD's data are reliable and have continuity over time and space.

- WRD has strong programs in long-term data collection, interpretation and assessment, and research and development. The continuing strength of all three elements is a critical success factor.
WRD has been successful because it possesses all of these attributes. Our future success depends on maintaining and improving these critical success factors.

\section{ABOUT A CHANGING WORLD}

WRD has a responsibility to look into the future and to anticipate emerging issues. This responsibility requires evaluating how events taking place today or projected for the future might influence existing programs or the development of future programs.

In looking outward, the single most important global trend that underlies many issues is population growth accompanied by economic growth. United Nations projections suggest that the world could reach a population of 8 billion people by 2025 (compared to today's 5.5 billion people). A growing world population and world economy will increase the global demand for food. U.S. agriculture could become more intensive, with an increased use of chemical and biological products that could affect the environment and create a greater demand for water. The use of genetically engineered plant species and other aspects of biotechnology may reduce fertilizer and pesticide use but create problems with which we have little experience.

The influences of global-scale issues will be especially important in situations where human pressure on ecosystems and health systems is greatest. For example, significant impacts from global climate change could be exacerbated where a continent is most crowded, where aspects of the civilization are least flexible, and (or) where effects are added to other stresses.

Although population growth will not be as rapid in the United States as in less-developed nations, growth will likely lead to more rapid suburbanization around major cities and of once sparsely populated areas. Recent trends in U.S. demographics indicate that people have and will continue to relocate in areas at risk from hydrologic hazards, such as coastal areas, flood plains, the base of hillslopes, and alluvial fans. 
Increasing development in the United States will result in increased pressure to use terrestrial and aquatic resources of all types.

There is likely to be increasing concern about human and environmental health. This concern could be driven by an environmental catastrophe, such as a significant waterborne disease outbreak somewhere in the United States, or by conclusive proof that chemicals in the environment are causing reproductive stress or other significant but sublethal effects in animals or humans. Environmental concerns also could be driven by an accretion of smaller challenges. Even in the absence of significant new environmental issues, the costs of monitoring and treating drinking water, cleaning up existing contamination, preventing future contamination through effective isolation of municipal and industrial waste, and taking precautions to prevent accidental releases of contaminants will exert pressure on the U.S. economy.

Advances in technology, such as instrumentation, models, and biotechnology, will enhance our ability to detect, analyze, mitigate, remediate, and disseminate solutions to waterresource problems. Advances in analytical chemistry are allowing improved detection of contaminants, while increased knowledge of biology and ecology brings greater understanding of the impacts of environmental perturbations. Improvements in measurement of streamflow in real time and improvements in models for decisionmakers will facilitate new abilities to manage water more effectively but also will demand the highest degree of reliability and availability of those data. The recent tremendous increase in use of the Internet and other advances in communication make it possible to disseminate hydrologic and other scientific information to both the scientific community and the general public instantly and inexpensively.

Within the context of the broad trends described above, five requirements for successful water-resource management are likely:

1. Active management for multiple uses.-Water resources will need to be managed simultaneously to provide water for human consumption, agriculture, industry, power generation, transportation, recreation, and habitat for fish and wildlife. These competing demands are already generating disputes in many parts of the country. In the future, needs for information will be greatest in arid regions, near the coasts, and in areas where water moves across State borders or between ground water and surface water.

2. Effectiveness and efficiency.-The public will demand greater efficiency and effectiveness in environmental regulation and resource management. Issues that will be increasing in importance include (1) prevention of pollution, thereby avoiding the high costs of environmental cleanup, (2) site-specific evaluation of risks to water resources that will justify more flexibility in enforcing regulations, and (3) use of watershed-based management that will build on local interests and minimize the inefficiencies that come from managing only a part of the resource.

3. Shift away from engineered solutions.-There will be less dependence on engineering solutions to water-quantity problems and more reliance on conservation and natural systems. Few new large water projects, such as dams or interbasin transfer systems, are underway or planned. Instead, water managers are using water conservation to reduce demand for water for irrigation, public supply, and industrial uses. Conservation has the added benefit of reducing the amount of water that must be treated after use. Waterresource managers are beginning to take advantage of natural systems to remove contaminants from water. For example, the use of natural or artificial wetlands in attempts to remove heavy metals from mine drainage is underway, and natural bacterial processes are being used to remediate contaminated ground water.

4. Demand for timely information.-The public expects warnings of flood events and other hydrologic hazards. Farmers, public water systems, recreational boaters, and 
environmentalists all want near real-time information on the quantity and quality of the water they use. Water data must be provided in a timely fashion and must also be accurate. Yet, increasing accuracy often requires more time. Water-resource managers and those who supply water data will need to be aware of and address this dynamic tension between accuracy and timeliness.

5. Increasing interest from the public.-People are concerned about the availability and quality of water. Few major water-resource decisions will be made without coverage by the media and the attention of interested citizens. It is expected that citizen action and monitoring efforts across the country, which include watershed-management associations, farmers and growers associations, and environmental interest groups, will play an increasing role in managing and monitoring water resources.

\section{STRATEGIC DIRECTIONS IN WATER RESOURCES DIVISION SCIENTIFIC ACTIVITIES}

WRD must continue to be relevant and responsive. To do this, some changes in the nature of our scientific activities and the way we conduct our work are necessary. First, several waterresource issues will require increased emphasis. Second, our ongoing scientific program will evolve to be more effective and to achieve needed balance among program components. This evolution of our current program is expected to take time and may not be completed within the 10year planning horizon; however, it is important to put ourselves on the trajectory to achieve our desired future. Third, we will make short-term (25 years) investments in technology and methodology to improve current capability.

\section{Priority Water-Resource Issues}

Nine water-resource issues have been identified for increased emphasis during the next 10 years. We believe that these issues will receive increased attention from the hydrologic community and need increased emphasis from us. Other issues and technical areas still have much value, and WRD will continue to collect data and conduct projects related to them. However, as projects end and new projects begin, we will direct more human and financial resources to the nine high-priority issues. For each issue, we provide some examples of activities that may be started or strengthened. Because of the importance of these issues to water-resource managers and the public, support for increased effort is expected from the Administration, Congress, cooperators, and partners.

WRD has a scientific infrastructure and much of the expertise needed to address these issues. We will build upon and enhance these strengths by forming partnerships with other USGS divisions, Water Resource Research Institutes, the academic community, and scientists from State, local, and other Federal Agencies. We also will work closely with land and water managers in the public and private sectors to better identify their information needs. Through these partnerships, we will form interdisciplinary teams to address the priority water-resource issues.

\section{Issue 1. Effects of urbanization and} suburbanization on water resources

Urbanization and suburbanization change the natural flow and recharge of water; introduce sediment, nutrients, and contaminants to surface and ground water; and increase demand for freshwater.

To address these changes, WRD will do the following:

- Develop tools necessary to manage watersheds effectively as the complex systems that they truly are. For instance, within the next 10 years WRD will work with the USGS National Mapping Division (NMD) and others to populate a quality-assured, user- 
friendly geographic information data base that contains coverages relevant to the understanding and management of water resources.

- Determine the effects that various land- and water- management practices have upon the quality and quantity of ground water and surface water. We will provide information to policymakers and resource managers as a basis for decisionmaking on issues, such as use of buffer zones along streams and around lakes, pesticide and fertilizer application rates, and other management practices.

Issue 2: Effects of land use and population increases on water resources in the coastal zone

By the year 2010, scientists estimate that 75 percent of the United States population will live within about 50 miles of the Atlantic and Pacific coast or one of the Great Lakes. Pressures on the coastal zone include an aging urban infrastructure, as well as demands for additional supplies of drinking water and a safe means to dispose of human and industrial waste that result from new growth. Population growth in the coastal zone also will add to stress on coastal ecosystems that provide recreation and critical habitat for waterfowl, shellfish, and finfish.

WRD will make an important contribution to coastal-zone water issues through the following:

- Provide estimated fluxes of major chemical species (especially nutrients) at key inflow points to the Nation's estuaries, coastal zones, and the Great Lakes.

- Conduct studies of saltwater intrusion into aquifers, movement of saltwater upstream in tidal rivers, and the effects of water withdrawals on coastal wetlands. For example, a synthesis of the extent and methodologies for analysis of saltwater intrusion into ground water along the Atlantic coast will be published within 3 years.

Issue 3. Drinking water availability and quality

Drinking water in the United States is safe and abundant in most places. Maintaining a safe supply of drinking water in the future will require considerable expenditure of money for protecting drinking water sources, treating drinking water, and monitoring drinking water quality. Competition between cities and agriculture for water will be intense, and disputes will arise in cases where withdrawal of ground water or surface water for water supply may impact aquatic habitat.

WRD will make a valuable contribution to the issue of drinking water availability and quality through the following activities:

- USGS Geologic Division (GD) has recently decided to focus more effort on geologic controls on ground-water resources. In cooperation with GD, we will provide an ongoing assessment of the availability and sustainability of the Nation's ground-water resources and of the major factors that affect these resources.

- Provide better descriptions of the quality of water available in aquifers under various management and growth scenarios. This function includes development of models that will help decisionmakers evaluate the consequences of management alternatives.

- Provide empirically based ground-water and surface-water quality vulnerability assessments, with a known level of accuracy that can be used by others to optimize monitoring expenditures for drinking water sources and for controls on land-use practices to protect source waters.

- Work with the U.S. Environmental Protection Agency (EPA), the Centers for Disease Control (CDC), and others to establish effective detection and monitoring methodologies for infectious, waterborne pathogens, such as Giardia and Cryptosporidium. We will relate the occurrence of these pathogens to land use and other factors.

- Work with the USGS Biological Resources Division (BRD) on the connections between infectious disease in animal populations and potential human pathogens in water. 
Issue 4. Suitability of aquatic habitat for biota

Aquatic habitat in this country has been severely altered by human activities, including construction, agriculture, and deforestation that increase sediment loads in rivers; construction of dams that impede migration of fish and other aquatic species; construction of dams and diversions that change the flow regime and modify habitat; drainage of wetlands areas; and increases in concentrations of nutrients and other chemicals in water.

Over the next 10 years, WRD will contribute to the understanding of the suitability of aquatic and riparian habitats for biota through the following activities:

- Study the effects of changes in flow regimes on aquatic and riparian communities as a result of reservoir operation and diversions or removal of dams and levees.

- Relate changes in sediment transport characteristics to riverine habitats, such as gravel and sand bars, backwater areas, and flood plains.

- Study the functioning of natural and constructed wetlands.

- Determine the effects of ground-water withdrawals on wetlands.

- Pay special attention to water-quality studies that include effects of low-level chronic exposure to multiple chemicals. In this and all other efforts that are focused on this issue, we will pursue opportunities for collaborative work with BRD.

\section{Issue 5. Waste isolation and remediation of contaminated environments}

There are several hundred thousand sites in the United States where the environment has been contaminated by past industrial, mining, military, agricultural, and commercial activity. The estimated cost of cleaning up these sites is as high as almost a trillion dollars. Costs of preventing future contamination are also significant for Federal, State, and local government, and the private sector as they attempt to manage industrial and domestic waste and find a suitable repository for radioactive waste.

WRD can make important contributions to risk evaluation, waste isolation, and remediation through its combination of knowledge of hydrology, chemistry, and biology and its ability to conduct complex interdisciplinary studies of environmental contaminants. Specifically, WRD will-

- Continue to conduct studies of the basic processes that control the transport and fate of contaminants.

- Increase emphasis on understanding the factors that make a system more or less vulnerable to contamination, thereby, providing valuable information for those who design wastedisposal sites.

- Work with partners in the private and public sector to provide the scientific basis for evaluation of the effectiveness and efficiency of remediation alternatives in the field.

\section{Issue 6. Hydrologic hazards}

Every year hydrologic hazards (floods, droughts, subsidence, landslides, and tsunamis) result in the death of about a hundred people, in the loss of hundreds of millions of dollars in damages, and in the disruption of thousands of lives. Better understanding of hydrologic hazards, better warning systems, and better risk information can minimize the consequence of these hazards.

Over the next 10 years, WRD will provide the information and understanding that will allow land and water managers, land-use planners, emergency management officials, including the Federal Emergency Management Agency, and the general public to understand the nature of risk before a hazardous event occurs, to monitor development of hazardous events as they occur, and to take action to minimize the effects of future hazardous events. Examples of specific activities that WRD will undertake to address these issues include the following:

- Increase the percentage of stream gages that are equipped to deliver real-time data. The entire system for delivery of stage and streamflow data will be made more reliable. We will take 
measures to ensure that critical data are delivered on a real time basis 24 hours a day, 7 days a week, especially during floods and other adverse conditions.

- Develop the capability to rapidly identify changes in flood-plain areas as a result of changes in land-use, climate, or engineering modifications and to revise estimates of flood frequency for these sites.

- In cooperation with the National Weather Service, we will develop a near real-time flood-warning system that will identify areas at risk by using watershed-based hydrologic, hydraulic, and digital-elevation models.

- Lead Federal Agencies to a new agreement on the methods for computing flood- and lowflow frequency statistics for both unregulated and regulated flow conditions.

Issue 7. Effects of climate on water-resource management

Recent extreme climatic variations have demonstrated that water-resource managers must develop their management systems in a context that assumes a wide range of possible climatic conditions, including the potential for significant and long-lasting departures from historically normal conditions.

WRD will provide some of the ingredients for a robust water-management strategy, which include-

- Conduct studies of long-term climate and proxy-climate records that cover several centuries in duration to bring a wider range of climatic variability into water-resource managers' plans.

- Provide hydrologic expertise and insights to interdisciplinary teams that are attempting to model future climate.

- Design river-basin simulation models that are useful for predicting flow conditions on the basis of climate, topography, land use, and engineering.

- Complete an assessment of the effects of development and climate variability on the interactions of ground water and surface water in the Southwestern United States.

Issue 8. Surface-water and ground-water interactions as related to water-resource management

Management of water resources has focused traditionally on either surface water or ground water as if they were separate entities. Yet, nearly all surface-water features, including rivers, lakes, wetlands, and estuaries, interact with ground water. Development of either water source affects the quantity and quality of the other.

WRD will provide leadership on this important issue through the following activities:

- Increase the number of studies of (1) effects of ground-water withdrawals on streamflows, surface-water levels, and aquatic ecosystems; (2) ground-water recharge from surfacewater bodies; (3) effects of climatic variations on the discharge from shallow ground-water systems; and (4) effects of ground-water/surface-water interactions on efforts to restore wetlands or construct new wetlands.

- Improve tools for simulating interactions between ground water and surface water to quantify the effects of human activity.

Issue 9. Hydrologic-system management, including optimization of ground-water and surface-water use.

Recent experience with resolution of difficult water-management and allocation problems has shown that a capability to simulate the characteristics of the hydrologic system, at watershed scale, is critical. What is needed are water-management models that are accepted by the various competing interests in water conflict. These models must be capable of showing the consequences of various water-management decisions over a wide range of hydrologic and climatic conditions.

In recent years, simulation models have been combined with techniques of optimization to address various water-resources problems. Combined simulation and optimization models 
account for the complex physical processes of the hydrologic system and identify the best management strategy for a particular objective(s) and set of constraints. The approach offers a rigorous way to provide information of management relevance. As applied in USGS studies, management agencies and others provide information on the objectives and management constraints, whereas USGS scientists provide expertise in simulation and optimization techniques and help to formulate the management problem in a simulation-optimization context.

- WRD will continue to be a neutral party in water- management disputes and to provide scientific information to help resolve the dispute by improving models to simulate the physical processes of hydrologic systems.

- WRD will work with Federal or State partners in selected locations to develop and use simulation and optimization (decisionsupport) models to help solve management problems, such as mitigation of seawater intrusion, allocation of water to users, and maintenance of optimal ground-water levels.

\section{Evolution of Ongoing Scientific Programs}

Overall, WRD's ongoing scientific and technical program can be described as a mix of (1) long-term data collection, (2) interpretation and assessment, and (3) research and development. During the next 10 years, these program components will evolve to be more effective, and we will work to achieve a better balance among them and among discipline areas.

Each of the three components has its own base of customers and constituencies, and each makes an important contribution to hydrologic understanding and the knowledge base needed for water-resource management and regulation. The real strength of WRD, however, comes from the combination of all three components and the linkages among them. For example, our ability to conduct assessments of the status of the Nation's water resources would be hindered without the long-term data-collection program. Similarly, our long-term data-collection program would be adversely affected without the new tools and understanding of hydrologic processes that come from research and development conducted by WRD scientists. Although the linkage and interdependence of the three program components are recognized, for purposes of this document each component and the new directions specific to that component will be described separately.

\section{Long-Term Data Collection}

The objectives of WRD's long-term data collection program are to collect, manage, and provide unbiased, scientifically based information that describes the quantity and quality of waters in the Nation's streams, lakes, reservoirs, and aquifers. This long-term program provides fundamental support for resource planning, development, management, and protection activities, as well as conflict resolution, scientific research, and warnings for water-related hazards throughout the Nation. WRD remains uniquely qualified to provide the basic hydrologic data to characterize the Nation's water resources. Important attributes of our long-term datacollection program include-

1. National scope, with associated economies of scale, including the infrastructure to support high-quality data collection and to manage and disseminate those data.

2. Nationally standardized field and laboratory methods and equipment, including procedures for quality assurance.

3. Research and methods development to improve data-collection methods and instruments.

4. Accurate and unbiased data and information products that are derived from ongoing evaluations of the hydrologic data base.

During the last several years there has been a decline in the long-term data-collection program. The number of continuous-record streamflow stations has been reduced; the number of stations included in the National Stream Quality Accounting Network (NASQAN) program and Hydrologic Benchmark Network program has 
decreased; and the ground-water-level network does not provide adequate national coverage.

The decline in basic hydrologic data collection is inconsistent with the increasing need for more comprehensive monitoring to support the intensive management and protection of water resources that will be needed as the Nation's population grows.

During the next 5 years, WRD will give high priority to redesigning and rebuilding its program of basic hydrologic data collection. Specific program issues, initiatives, and priorities are discussed below.

\section{Surface Water}

WRD will undertake the following strategic efforts in the next 5 years to enhance the streamflow data-collection program:

- WRD currently maintains a national network of about 7,000 streamflow monitoring stations. We will continue to maintain and enhance this network. We will identify a core set of stations that fulfill critical Federal functions and seek reliable Federal funding that will ensure their long-term support. This core set would include index stations that represent environmental trends in watersheds in each of the Nations' ecoregions, stations that document the flow of each of the 352 hydrologic accounting units, stations that are mandated by River Basin Compacts and Supreme Court decrees, stations that are used for river forecasting, long record "legacy" stations in watersheds not subject to regulation or diversion, streamflow stations that support national water- quality networks, and stations on major rivers that flow across State or international borders. Most gages in the entire network will provide real-time data that will be available on the Internet. Our goal is to provide high-quality data from the streamflow monitoring network at all times. Some individual stations will be affected by severe ice conditions or damaged during floods, but we will place a high priority on documenting ice conditions and repairing damaged equipment at stations that are critical for flood monitoring.

- Enhance our manner of providing streamflow data from being primarily daily average flows at specific gage locations to being continuous time series of flow data.

- Significantly reduce the cost of providing streamflow information. We will investigate use of instruments to measure streamflow that do not have to be submerged in the stream. Simplifying and streamlining records computation in the office are other potential means of reducing cost. As a first step, we will design and conduct a comprehensive internal review of the streamflow-gaging program processes and methods to identify opportunities for cost reductions through streamlining and modernization.

- Evaluate the feasibility of using a national-level contract(s) for the routine construction, safety inspection, and maintenance of streamgaging infrastructure, such as gage houses and cableways, to achieve economies of scale and reduce the use of Federal employees to perform these ancillary functions.

- Conduct a comprehensive analysis of the national streamflow network to assess the value of gages in meeting program objectives. The findings will be used to explain the value of the streamflow network in a quantitative fashion to customers and cooperators. This analysis will also provide a basis for funding allocations for network operations and maintenance.

\section{Ground Water}

Strategic efforts WRD will undertake in the next 5 years to enhance the ground-water datacollection program include the following:

- USGS ground-water data will be more accessible over the Internet. This accessibility will provide an efficient and ready source of ground-water data to agencies and private consultants who need such information on a day-to-day basis. 
- Implement a long-term, spatially distributed network of wells whose water levels primarily reflect natural recharge conditions and climatic variability.

- Evaluate the need for 5- to 10-year synoptic water-level measurements of major aquifers that cross state boundaries and that are conducted on a rotational basis as part of the development of future plans for the GroundWater Resources Program.

\section{Water Quality}

To enhance the water-quality data base, the WRD will undertake the following strategic efforts over the next 5 years:

- Increase collection of water-quality data that directly relate to highly visible and critical human-health and aquatic-health issues, such as hypoxia, toxic algal blooms, mercury contamination, and nutrient enrichment.

- Work with State agencies and EPA to improve design of surface-water quality monitoring networks to better estimate loadings of contaminants from non-point sources for purposes, such as calculation of total maximum daily loads (TMDL's).

- Lead in the integration of small, pristine basin networks of USGS and other agencies (U.S. Forest Service, National Science Foundation, and Agricultural Research Service) as reference sites for comparison to basins that have been directly affected by human activities.

- Interpret existing and new data from small basins to demonstrate the relation of stream quality to the quality of atmospheric deposition.

- Explore the wider use of immunoassays, field sensors, and other techniques to collect highquality water-quality data at reduced costs.

- Develop analytical methods and sampling strategies to detect emerging environmental contaminants, such as pesticide degradation products and pharmaceuticals present in human and animal waste.

\section{Water Use}

The WRD will undertake the following strategic efforts in the next 5 years to enhance the water-use data-collection program:

- Provide more comprehensive water-use data and analysis of water-use information to quantify the stress on water resources.

- Collaborate with university scientists whose work could complement that of the internal water-use program or who could provide expertise in those areas where the USGS has very little or no capability, such as in the economic aspects of water use.

\section{Interpretation and Assessment}

WRD interpretive and assessment studies allow us to make contributions to issues that are useful to decisionmakers at all levels and to the general public. They keep us relevant and highlight emerging issues of importance to society. An important aspect of these studies is that data are turned into information of direct use to decisionmakers.

WRD has a key role to play in the waterresource community because we maintain a national perspective and can describe hydrologic systems that cross political boundaries. We are able to integrate data-collection and interpretive studies that are conducted across the country to build the bigger picture. These synthesis efforts are made possible because data are produced in a standard fashion and stored in a common data base. These syntheses are made easier when there is an overall framework for local projects.

WRD will undertake the following strategic efforts in the next 5 years to enhance interpretation and assessment studies:

- Design study products that will be more useful and relevant to solving problems that are faced by water managers and other decisionmakers. For example, we will increase the development of models and other decision-support tools, including evaluation of alternative management scenarios, in interpretive and assessment studies. 
- Develop a system to track the use and usefulness of interpretive products to determine who uses them and how they are used. This feedback will form the basis for producing products that are more useful and relevant to decisionmakers.

- Increase the level of coordination among WRD regions to identify national issues that can be addressed by the Federal-State Cooperative Program and, thereby, increase opportunity for national synthesis products.

- Work directly with decisionmakers at all levels to provide the best available understanding of emerging issues. Often, decisions have to be made rapidly, and as a result, there is a need to make decisions that are based on incomplete understanding. In those cases where decisions are going to be made, regardless of the level of understanding, we will work with decisionmakers so that their decisions will be based on the best scientific knowledge available.

- Interpret and analyze data in our national water data bases to accomplish informationsynthesis objectives. An example of such an analysis is an assessment of trends in the annual and seasonal average flow of streams throughout the Nation. These types of analyses of our national data base will be done on a recurring basis.

\section{Research and Development}

Research and development provide the scientific infrastructure (expertise, accumulated knowledge, tools and techniques) that keeps WRD in the forefront of the hydrologic sciences and helps us to achieve our mission. Our scientists conduct both fundamental research that has longterm payoff and immediately relevant, problemsolving research that has short-term benefits. WRD's overall research effort has two components-(1) centrally managed research that is located primarily at three USGS regional centers and (2) distributed research that is located primarily in district offices. In the future, these two components, or research models, will retain their unique structural characteristics but will increasingly collaborate, communicate, and build on their commonalties.

While maintaining the internationally recognized quality of our research, we will continue to balance expenditures on research with other needs of the division. Decisions to hire new researchers in either of the research models described above will consider needs of the operational program, the national balance of discipline expertise, and new directions in hydrologic sciences. The concept that every major subdiscipline in hydrology should be covered in WRD must be reconsidered if resources shrink. If resources grow, then covering the base of subdisciplines that are relevant to the WRD mission will become more important than growing great depth in any single subdiscipline. In either case, our research staff will be developed around the principle of maintaining a balanced distribution of discipline expertise, rather than developing expertise solely on a geographic or issue-by-issue basis.

WRD will undertake the following strategic efforts to enhance research and development:

- Research will be more interdisciplinary in the future to address complex problems and will be conducted more by scientists from several disciplines working together.

- Linkages between research advisors and discipline specialists in the technical offices, in regions, and in districts will be improved. Improved communication will lead to a common understanding of the WRD's research capabilities and the needs of the operational program, which will influence the directions of research.

- Studies of emerging issues will take advantage of the accumulated knowledge base that has been developed from long-term studies of specific ecosystems or specific hydrologic problems.

- Research activities will increasingly include collaboration with the academic community, postdoctoral research associates, scientists on term and sabbatical appointments, and students. 


\section{Balance Among Major Program Components}

The keys to WRD's future success are a strong long-term data-collection program, a strong program of interpretive investigations and national and regional assessments, and a strong research and development program. We must also maintain an appropriate balance among these scientific activities. Ideally, the percentages of total available funds for the three components should be about 40 percent for long-term data-collection, about 45 percent for interpretation and assessment, and about 15 percent for research and

development. The relative proportion of these three components will be out of balance if either long-term data collection or interpretation and assessment funding falls below 30 percent of total program or if research and development falls below 15 percent.

These three program components are not really separate; they are interdependent and linked. For example, projects with a primary focus on research or assessment may collect hydrologic data systematically over a long time period. Similarly, long-term data collection and interpretive investigations rely on the scientific infrastructure and accumulated knowledge that has been developed by researchers. Therefore, the percentages given above are approximate.

The history of the mix among program activities is as follows:

\begin{tabular}{lrrr}
\hline Percentage of overall funds for- & $\mathbf{1 9 8 2}$ & $\mathbf{1 9 9 0}$ & $\mathbf{1 9 9 8}$ \\
\hline Long-term data collection $^{1}$ & 37 & 36 & 34 \\
Interpretation and assessment & 47 & 45 & 48 \\
Research and development & 16 & 19 & 18 \\
\hline
\end{tabular}

${ }^{1}$ Long-term data collection is defined as data that are collected consistently over a period of at least 5 years and typically for a much longer period of time. Thus, even though almost all projects collect basic hydrologic data, only those sites that are monitored continuously for at least 5 years are included in calculating the percentage of funds spent on long-term data collection.

From 1982 to 1998 , there was only modest funding growth above inflation for streamgages and real declines in funding for NASQAN and ground-water monitoring. This is of special concern because of the importance of long-term data collection for water-resource management and to determine the effects on water resources of climate variability and land-use changes on water resources.

- WRD will work with DOI, Office of Management and Budget (OMB), and Congress to begin to shift its overall program to increase the funds available for long-term data collection.

\section{Balance Among Discipline Areas}

WRD must also maintain a balance among the water-resource discipline areas. Ideally, this balance would be about 30 percent of total program funds spent for data collection and investigations that are related to surface-water quantity (includes floods), and about 25 percent for data collection and investigations that are related to ground-water availability. Of the remaining funds, about 25 percent would be spent for data collection and investigations of surfacewater quality, including geomorphology, and ecology, and about 20 percent for ground-water quality. The ideal funding level for surface water is higher than that for ground water because of the extent of surface-water monitoring needed for flooding and hazard warning. Overall, there is a bias towards quantity and availability of water resources because of WRD's unique position as the Nation's primary collector of these data. WRD's overall program will be out of balance if any one of the four components falls below about 20 percent or rises above about 35 percent.

WRD will institute a system to track the percentage of scientific effort devoted to each of the four discipline categories described above-surface-water quantity, ground-water availability, surface-water quality, and groundwater quality. This is a different discipline breakdown than the one that has been used during the last 15 years when we used the categories ground water, surface water, water quality, and general hydrology to track our work. The history 
of the mix of disciplines in WRD programs is as follows:

\begin{tabular}{lrrr}
\hline Percentage of overall funds for- & $\mathbf{1 9 8 2}$ & $\mathbf{1 9 9 0}$ & $\mathbf{1 9 9 8}$ \\
\hline Ground water & 20 & 20 & 15 \\
Surface water & 32 & 32 & 32 \\
Water quality & 22 & 23 & 25 \\
General hydrology & 26 & 25 & 28 \\
\hline
\end{tabular}

During the last 8 years (1990-98), there has been growth in the water-quality area. This growth primarily results from increased work for the Department of Defense and the growth of the NAWQA program. The surface-water component has stayed constant between 1982 and 1998 but the number of interpretive studies, which were never a large percentage of the surface-water component, have had an overall decrease. The discipline that had the most significant decrease was groundwater resources, primarily because of completion of the Regional Aquifer-System Analysis Program.

As competition for water increases nationwide, the importance of ground-water and surface-water data, assessments, and models will continue to increase. The water-management community continues to point out the important role they believe the USGS should play in describing ground-water and surface-water systems and the relation between them, as well as in modeling these systems so that various management scenarios can be simulated to provide for sound long-term water-management decisions. WRD's ground-water and surface-water programs are currently too small to meet all these needs.

- WRD will work with DOI, OMB, and Congress to seek opportunities to increase the groundwater and surface-water quantity components of its program, including long-term data collection, assessments and modeling, and research and development.

\section{Investments in New Capabilities}

WRD will make significant investments in new tools and capabilities to improve our field and laboratory methods, instruments, hydrologic models, data-base software, and information dissemination. An important aspect of this investment strategy is that we will significantly improve the transfer of new capabilities to our operational program so that we can better address priority water-resource issues and improve the effectiveness of our work and products.

The process of investing depends on the availability of the underlying scientific knowledge and technology. This process is a major responsibility of the research staff of WRD and also requires an understanding of the need for the tools. This comes about through communication among all parts of the WRD_-district staff, regional staff, National Research Program, and headquarters units. The responsibility for providing a focus for the discussion and prioritization of needs and for assigning the individuals and needed resources for the development, testing, documentation, and training associated with these investments rests primarily with the Offices of Surface Water, Ground Water, and Water Quality, Federal program managers, and the Offices of the Assistant Chief Hydrologists.

The following discussions describe some of the top investment priorities for the next 2 to 5 years as opposed to the 10-year range that is the general rule for this document. These priorities must be reevaluated on a frequent basis.

\section{Field and Laboratory Methods}

The greatest needs for field and laboratory methods are (1) faster and less expensive ways to collect samples for chemical analyses that adequately represent the environment being characterized and (2) development of laboratory methods for analysis of contaminants at the very low concentrations at which they may affect human and aquatic health. 
High-priority methods for development are described below:

- Investigate alternative approaches for collection of surface-water samples to reduce costs and limit sample contamination.

Alternative approaches that will be evaluated include point samples or dipped samples as surrogates for discharge-weighted samples.

- Develop standard procedures for separation of aqueous and solid phases of trace elements in ground water and surface water to help evaluate the effects of these elements on human and aquatic health.

- Improve analytical methods for pesticides and pesticide degradation products.

\section{Instruments and Technology}

Although WRD obtains most of its instruments from the private sector, division scientists and technical experts have an important role in designing, quality assuring, and field testing new instruments. The WRD will continue to maintain facilities for testing and quality assuring existing and new instruments. In the next 5 years, we will increase our efforts to identify promising technology developed in other scientific or engineering fields that could be modified to collect data on water quantity or quality. We will also work with instrument designers and developers in other Federal Agencies and the private sector to bring them to our field sites where the instruments can be tested.

High-priority instrument development needs are described below:

- Develop nonsubmersible instruments to measure water depth, streambed elevation, and stream velocity to improve the efficiency, accuracy, and reliability of the streamgaging program.

- Develop, or work with others to develop, and test instruments that are able to sense chemical constituent concentrations continuously or to integrate the concentrations over some period of time. In the near term, advances in sensor technologies are expected for chemicals that occur at high concentrations. Reliable in-situ determination of the very low concentrations that characterize trace metals and organic compounds is a more significant technical challenge.

- Invest in state-of-the art instrumentation and emerging technologies to ensure that USGS ground-water science will meet present and future needs for information. Technologies that will get special attention include (1) passive systems and in-situ measurements that use fiber optics, laser technology, and other advanced technologies for measurement of properties and biogeochemical characteristics; and (2) advanced surface and borehole geophysical techniques.

\section{Hydrologic Models}

WRD is an international leader in the development and application of hydrologic modeling software, which is developed by our scientists to meet the mission of the division and then made available at no cost to the entire hydrologic science community. As water-resource issues evolve, new modeling capabilities and enhancements to existing modeling software are needed on a continuing basis to keep us on the forefront of quantitative hydrology.

To meet this increasing demand, we will do the following:

- Develop a new generation of computer models to simulate (a) watershed-scale responses to climate and land-use changes; (b) openchannel surface-water flow; (c) the interaction of ground water and surface water, including lakes, streams, and wetlands; and (d) water chemistry and sediment transport. These models will be linked with decision-support systems for science-based water-management decisions. The models will be designed to become the models of choice for the scientific community. 
- Address the problem of quantifying uncertainties in predictive models so decisionmakers can evaluate the reliability of their decisions.

- Integrate results of surface and borehole geophysical surveys for scientific visualization and produce data in a format that can be directly used in ground-water modeling.

- Connect all of our core hydrologic models to graphical user interfaces and scientific visualization software. These tools make models easy to use, facilitate hypothesis testing during model calibration, and greatly enhance the visualization of model results. To allow modifications of USGS modeling software over time, the scientific core of these models will remain cleanly separable from the preprocessing and postprocessing software, which is expected to be commercial software.

\section{Data-Base Software}

The goals for WRD data-management systems are to (1) eliminate any duplication of data-entry activities, (2) automate data transfer as much as possible, (3) provide powerful and easyto-use tools for data-processing and data-quality control, and (4) provide tools to easily retrieve data in the volumes and formats that are useful to USGS employees, cooperators, and the general public.

Principles for development of a national water-information data base for WRD are as follows:

- To the extent possible, use commercially available software and contractor support for data-base development.

- WRD data should be easily accessible to other organizations and the general public.

- The primary means of access to the data for all users other than those that are directly involved in creating the data will be through the Internet. Use of the Internet ensures that the access systems will be virtually independent of the user's computer platform or operating system.

- Data retrievals for multiple States should be as simple as retrievals from single-States. Users should not have to navigate among a set of USGS servers to find the data they need.

- There should be only one official site for any data value or set. However, release of copies of specialized subsets of the whole data base through the Internet or a CD-ROM is encouraged provided that the metadata associated with the data set contains a disclaimer that explains when the data were copied from the official files.

- Users should have access to the full information content of WRD monitoring data sets. Users should be able to reproduce the continuous record from a monitoring station except for those periods when the daily values are estimated because of ice or other anomalous conditions.

- The system should comply with the minimum data elements as defined by the Intergovernmental Task Force on Monitoring and comply with data exchange or metadata requirements of the Federal Geographic Data Committee. This compliance should ensure the ability to import and export data between the WRD system and other data systems.

- WRD will control entry of data into its data base and will make the decision to enter other agency data on the basis of direct knowledge of the methods and quality assurances used by the data producer. We will vigorously promote the use of our data-base software by other data producers with a goal of making it easy to access the producer's data.

\section{Information Dissemination}

The primary stakeholders for WRD information and technology are (1) water managers with operational, day-to-day responsibilities for public-water supply and distribution, wastewater treatment, reservoir operation, power generation, and flood 
forecasting; (2) environment and natural resource managers and planners in local, State, and Federal Government and non-governmental organizations; and (3) the science and engineering community, including universities, water supply and treatment industries, mining and energy industries, agriculture and irrigation industries, and engineering and consulting firms.

The goal of WRD's information dissemination activities is to get our data, reports, methods, and models to our customers and partners in a form and within a timeframe that will allow them to use our products to demonstrably affect society's needs to make a better world. As a science bureau, we cannot ensure that our products are used. However, we have a responsibility to take steps that will foster their use. It is essential, therefore, that we actively work with our customers and partners to do the following:

- Identify high-priority users of WRD products. This identification will proceed by systematically defining desired outcomes and mechanisms to realize these outcomes, and by developing complete lists of possible customers and partners.

- Develop and implement launch strategies to ensure that WRD products are effectively delivered to high-priority users.

- Continue to use emerging technologies to improve the delivery of products to highpriority users.

- Use feedback mechanisms to assess and improve product delivery.

Examples of specific goals for the information-dissemination activities include the following:

- WRD will reduce the time it takes to produce quality reports. We live in an information age, and we must get reports out to our customers much sooner. WRD will reduce by one-fourth the average elapsed time between the author submitting the first draft of the report for review and the final approval of the report from the baseline established during 1997.
- USGS will provide the capability, through the Internet, for anyone with Internet access to obtain real-time streamflow, ground-water levels, and water-quality characteristics from monitoring stations that are equipped with appropriate telemetry. We also will provide the capability for obtaining long-term hydrologic characteristics from locations with historical data and estimates of hydrologic characteristics from any other location in the Nation.

- Within 2 years, WRD will develop and adopt prescribed formats that will be used by every district to serve selected hydrologic information over the Internet. The result will be a series of pages that have an identical appearance, regardless of where they originate, and provide easy access to the types of data that are typically collected by all WRD districts. This consistency will greatly facilitate access to our products by both external customers and our employees.

- Within 5 years, we will develop a National Aquifer Data Base that will provide information and digital coverages for the Nation's principal regional aquifer systems via the Internet.

\section{NEXT STEPS}

A shared understanding of strategic directions is especially important for an organization like WRD because we have a distributed management structure. Many, if not most, decisions that affect our customer base and human- and financial-resource allocations are made in district offices, research branches, and other major field offices. Accordingly, the new directions contained in this document will be implemented at all levels of the organization. In some cases, special groups of individuals, such as the Computer Policy Advisory Committee or the Laboratory Advisory Committee, will be asked to develop specific implementation plans to move us forward in a specific area. Other directions will be 
implemented as district personnel discuss new project opportunities with cooperators or as research scientists decide future directions for their work. Participation by headquarters staff will be important in developing the ideas for investments and for our operational practices.

The process of developing this strategic directions report has caused WRD senior management to debate, evaluate, and reach new understanding on a wide range of issues. Many directions, priorities, and activities described in this document were implemented even before the document was finalized. Other strategic directions will be implemented over a longer period of time through the combination of many decisions by WRD management on topics, such as budget formulation, internal budgeting decisions that are related to investments, program development, and division policies. Within the first 6 months after release of this report, we will prioritize the remaining directions and activities, and appropriate groups will develop plans for rapid implementation of the highest priority items.

As WRD moves into the 21 st century, we must be positioned to take advantage of new opportunities and successfully respond to new challenges. In the next 10 years, some changes are expected in what we do and how we do it. New water-resource issues will emerge; we will be prepared to meet them. There will be new customers and partners who have needs for waterresource information; we will be open to them. New technology will be developed that will allow us to do our jobs more effectively and efficiently; we will work to acquire this technology. It is the hope of the authors that this document represents a significant step toward defining our future and moving toward it. 